ZOOLOGIA 27 (6): 961-964, December, 2010

doi: $10.1590 /$ S1984-46702010000600018

\title{
Changes in the size of cephalic salivary glands of Apis mellifera and Scaptotrigona postica (Hymenoptera: Apidae) queens and workers in different life phases
}

\author{
Silvana B. Poiani ${ }^{1,2} \&$ Carminda da Cruz-Landim¹ \\ ${ }^{1}$ Departamento de Biologia, Instituto de Biociências, Universidade Estadual Paulista. Avenida 24A, 1515, Bela Vista, \\ 13506-900 Rio Claro, SP, Brazil. \\ ${ }^{2}$ Corresponding author. E-mail: spoiani@yahoo.com
}

\begin{abstract}
The bee species of the Apinae, in addition to the thoracic salivary glands, possess a pair of cephalic glands originating as branches of the excretory duct that crosses the head. These glands are known as cephalic salivary or labial cephalic glands. The degree of development of these glands in newly emerged, nurse and forager workers and virgin and egg-laying queens of Apis mellifera Linnaeus, 1758 and Scaptotrigona postica Latreille, 1807 were evaluated by measuring the secretory alveolar units. The area of the secretory alveoli, measured in total gland preparations, was used to evaluate differences in size. In both species, gland size was found to increase progressively from newly emerged workers to foragers and from virgin to egg-laying queens. A statistical analysis revealed significant differences $(p \leqslant 0.05)$ in the area of gland alveoli of workers in different life phases in both species, and between S. postica virgin and egglaying queens, but not between A. mellifera queens. In the case of workers, this suggests cephalic salivary gland secretion has a function in forager activity and, in queens, a possible pheromonal function.
\end{abstract}

KEY WORDS. Bee; labial gland; morphometry; pheromone; salivary system.

All insects have a pair of salivary glands with secretory units located in the thorax and the excretory duct. The secretion of these glands is delivered to the head's labial segment. However, in some bees, especially in species of Apinae, the branches of the excretory duct differentiate into a pair of cephalic glands called head salivary glands (Cruz-Landim 1967) or cephalic salivary glands (CSG).

These glands produce an oily secretion, whereas that of the thoracic gland is aqueous (Delage-Darchen et al. 1979, Simpson 1960, Simpson et al. 1968). Several functions have been proposed for the CSG secretion, such as wax softening (Heselhaus 1922), nest building, lubrication of mouthparts (Simpson 1960), and the construction of scent trails to indicate food source locations (JARAU et al. 2004, Schorkopf et al. 2007).

Apis mellifera Linnaeus, 1758 and Scaptotrigona postica Latreille, 1807 are two eusocial bee species belonging to the Apinae. According to Heselhaus (1922), Inglesent (1940), Simpson (1960, 1961, 1963) and Katzav-Gozansky et al. (2001), the cephalic salivary gland in $A$. mellifera reaches its maximum size in the forager worker. Nevertheless, previous studies about the CSG have not considered variations in the degree of development of individuals displaying different functions in the colony. Moreover, the aforementioned studies involved only worker bees. To fill this gap, the present work compares the size of cephalic salivary glands in the female castes carrying out different life phases and tasks in the colony.

\section{MATERIAL AND METHODS}

In this study, workers and queens of $A$. mellifera and $S$. postica were used. The individuals were captured in colonies maintained in the apiary of the Instituto de Biociências, Universidade Estadual Paulista (UNESP), Rio Claro, state of São Paulo, Brazil. The workers were captured according to their tasks in the colony or life stages, i.e., three groups of workers were used: 1) newly emerged and therefore very young (collected just after leaving their brood cells); 2) nurses or middle-aged (collected while tending the brood); 3) foragers or oldest workers (collected when returning to the nest). Two kinds of queens were used: virgin and fecundated egg-laying. The virgin queens from A. mellifera were artificially produced.The cephalic salivary glands (CSG) of all individuals were dissected under a stereomicroscope in Bouin fixative and placed on histological slides at room temperature for one hour. Each individual possesses a pair of glands. Ten alveoli of each gland from 10 different workers in each life phase were measured; 100 alveoli were thus randomly selected for each worker group.

In the case of queens, the number of individuals measured varied according to their availability. However, 10 alveoli 
selected randomly from each individual were measured. The $S$. postica queens were four virgins (40 measurements) and five egg-laying (50 measurements). In A. mellifera queens, the measurements involved 10 virgins (100 measurements) and one egg-laying (10 measurements).

The alveolar areas $\left(\mu \mathrm{m}^{2}\right)$ were measured using image analysis software (Leica QWin 550). The values obtained were transformed logarithmically. As the data presented normality and homogeneous distribution, a parametric statistical test, the variance analysis (ANOVA) for comparison of the averages obtained in the different studied groups ( $\mathrm{p} \leqslant 0.05)$, was used. The Tukey's test was applied to verify among which groups the differences occurred. The statistical analysis was carried out using the SYSTAT 10 Software.

\section{RESULTS}

Differences in size and production of secretion by the CSG were observed during the bees' lifetime, but the use of the secretion made by these glands is not completely understood. Besides, only the workers have been studied.

As most of the CSG increase in size is due to secretion accumulation in the alveoli lumen, the aim of the present study was to search for a possible relationship between the variation in the size of the gland's alveoli and the function performed by the individual, in an attempt to understand the importance of the secretion in the bees' activities.

Apis mellifera. The ANOVA showed significant differences among the workers' life stages (AGE) ( $\mathrm{p}=0.001$; Tab. I) and Tukey's test indicated significant differences between nurse and forager workers. The average size of alveoli of newly emerged workers was intermediary between nurses and foragers, without significant statistical differences. The graph (Fig. 1) shows the average alveolar size in each worker group. The variation in the alveolar area within each worker group was also analyzed [GL(AGE)] and significant differences in alveolar area were found within the workers' life stages $(\mathrm{p}=0.002)$ (Tab. I).

The differences in average alveolar size in virgin and egglaying queens were not statistically significant $(\mathrm{p}=0.623$; Tab. I and Fig. 2).
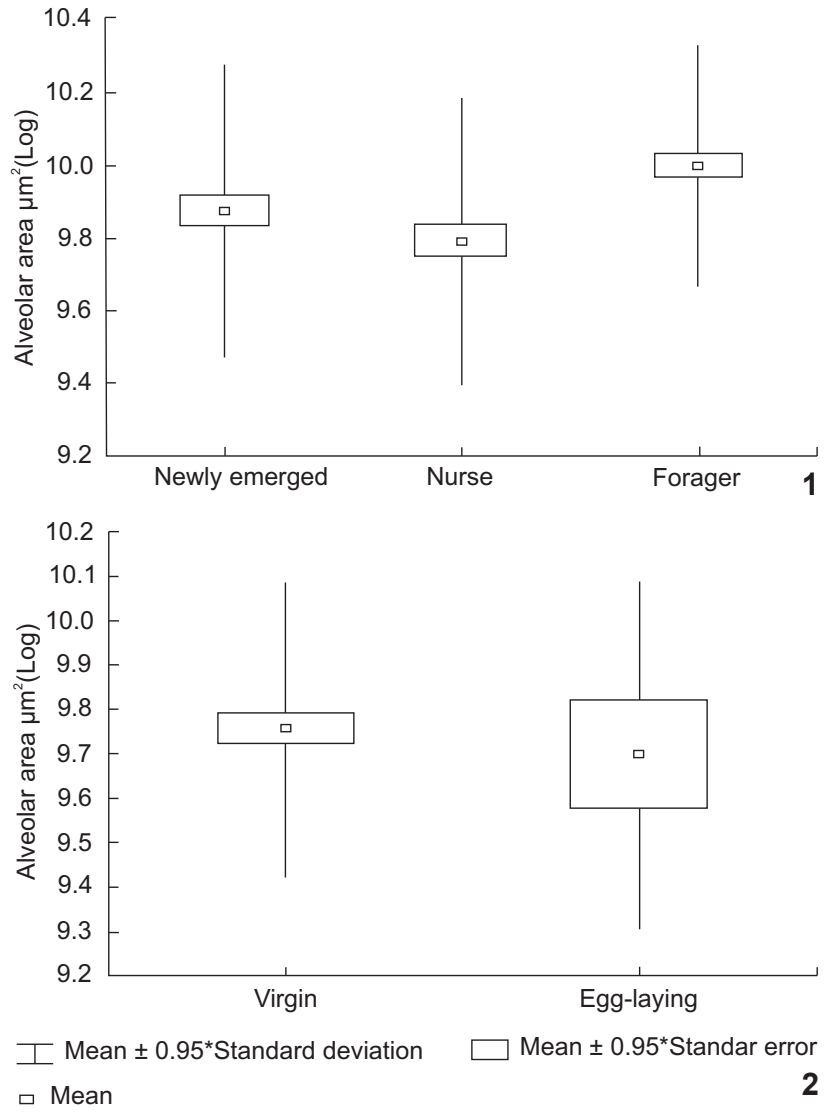

Figures 1-2. Graphs of alveolar average size in A. mellifera workers (1) and queens (2). Forager workers present the largest alveolar average and there is no difference between queen life phases alveolar average.

Scaptotrigona postica. The average alveolar size of the glands of workers varied significantly among life stages $(\mathrm{p}=0.000)$ and within each stage $(\mathrm{p}=0.000$, Tab. II), a situation similar to that found for A. mellifera workers. The Tukey's test showed differences in the average alveolar size of all worker

Table I. Variance analysis (ANOVA) of the alveolar area from cephalic salivary glands of $A$. mellifera workers and queens. Note the significantly difference $p$ value $(p \leqslant 0.05)$ among workers of different and also within each workers group. There is non-significant difference $(p>0.05)$ between virgin and egg-laying queens. Significance $p \leqslant 0.05$.

\begin{tabular}{|c|c|c|c|c|c|}
\hline Source of variation & Sum of squares & Degrees of Freedom & Mean square & Mean square ratio & $\mathrm{p}$ \\
\hline \multicolumn{6}{|l|}{ Workers } \\
\hline AGES & 2.125 & 2 & 1.062 & 7.402 & 0.001 \\
\hline GL(AGES) & 7.905 & 27 & 0.293 & 2.040 & 0.002 \\
\hline Residual & 38.753 & 270 & 0.144 & & \\
\hline \multicolumn{6}{|l|}{ Queens } \\
\hline AGES & 0.031 & 1 & 0.031 & 0.244 & 0.623 \\
\hline Residual & 13.718 & 108 & 0.127 & & \\
\hline
\end{tabular}

ZOOLOGIA 27 (6): 961-964, December, 2010 
Table II. Variance analysis (ANOVA) of the size of cephalic salivary glands of S. postica workers (III) and queens (IV). Note the significatly different $p$ value $(p \leqslant 0.05)$ among workers and between virgin and egg-laying queens. Significance $p \leqslant 0.05$.

\begin{tabular}{cccccc}
\hline Source of variation & Sum of squares & Degrees of Freedom & Mean square & Mean square ratio & $p$ \\
\hline Workers & & & & & \\
AGES & 60.424 & 2 & 30.212 & 404.780 & 0.000 \\
GL(AGES) & 14.827 & 27 & 0.549 & 0.000 \\
Residual & 20.152 & 270 & & & \\
Queens & & 1 & 44.121 & 546.624 & 0.000 \\
AGES & 44.121 & 7 & 0.156 & 1.932 \\
GL(AGES) & 1.091 & 81 & 0.081 & 0.075 \\
Residual & 6.538 & & & \\
\hline
\end{tabular}

groups (newly emerged, nurse and foragers). We found that the average alveolar area tends to increase as the individual ages. The smallest alveolar area was found in newly emerged workers and the largest in foragers (Fig. 3).

Virgin and egg-laying queens showed statistically significant $(\mathrm{p}=0.000$, Tab. II) size variances, with virgin queens possessing smaller alveoli than egg-laying ones (Fig. 4).

Our findings indicate that the CSG secretory units are larger in older workers of both species, and also in S. postica egglaying queens. The increase in alveolar size is due to an enlargement caused by the accumulation of secretion in the lumen.

\section{DISCUSSION}

The CSG of A. mellifera reaches its maximum development between 17 and 41 days of age, i.e., the period of transition (17 days) from tasks inside the nest to those outside, which is completed in 41 days, according to Heselhaus (1922), Inglesent (1940) and Simpson $(1960,1961,1963)$. Although these authors based their findings only on observations, their results were confirmed statistically by KatZAV-GozAnSKY et al. (2001), who showed that $A$. mellifera forager workers contain significantly more secretion in their gland alveoli than nurses, but they didn't analyse newly emerged workers. The authors attributed these findings to the behavior of workers but not to their age.

The increase in CSG alveoli size in workers of both species follows almost the same pattern, with foragers showing the largest alveoli. However, the differences in alveolar size within $S$. postica are more marked than within A. mellifera. In $S$. postica, all life stages show differences, but in A. mellifera these differences are limited to nurse and forager bees. Our findings for $A$. mellifera are consistent with those reported previously by KatZav-GozANSKY et al. (2001). However, the average alveolar area in newly emerged workers is not significantly different from foragers' (Fig. 1).

Some inferences can be made about the possible function of these glands in the workers of both species based on their presence and degree of development. The variations in the size of secretory units reflect their ability to produce and
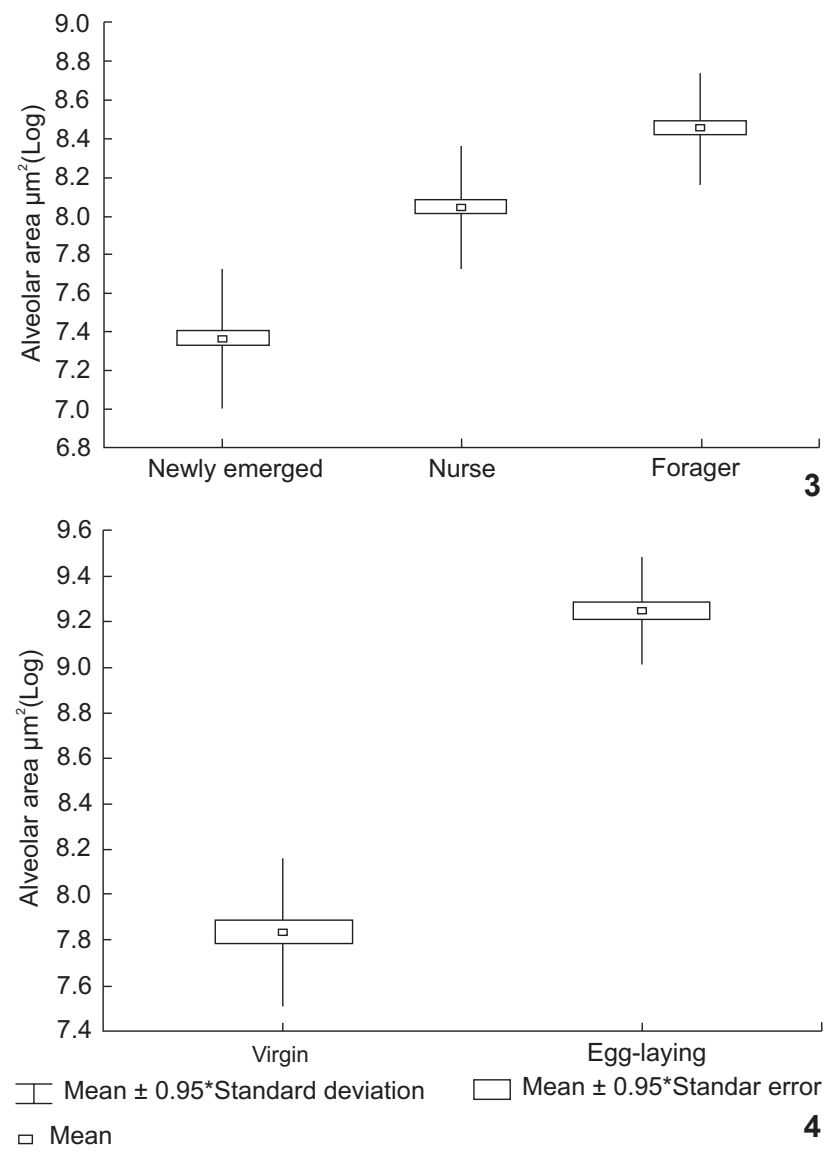

Figures 3-4. Graphs of alveolar average size in S. postica workers (3) and queens (4). Alveolar average size increases from newly emerged to forager workers and from virgin to egg-laying queens.

store secretion. Therefore, it seems clear that, among workers, the foraging activities require the largest amounts of secretion.

The main function of foragers is to gather several kinds of materials, mostly food, for the nest. The secretory cells are rich 
in vesicles typical of lipid secretion (POIANI \& CRUZ-LANDim 2009), which may have a function in those activities, aiding in the collection of materials, or serving as a pheromone to identify individuals returning to the colony or to produce scent trails (JARAU et al. 2004, SсHоRкорF et al. 2007). However, Simpson's hypothesis (1960) that the secretion serves to lubricate the mouthparts cannot be ruled out. Moreover, the secretion may be part of the surface substances that identify the individual (BЕRTSCH et al. 2005).

The glands of $S$. postica egg-laying queens are considerably larger than those of virgin queens. The function of the queen is restricted to oviposition, so fecundated queens of this species do not leave the colony. Therefore, the function of the queen's glands may differ from that of workers. One possibility is that the secretion of the queen's gland may be integrated with her body's surface compounds, serving as a recognition pheromone, since PoIANI \& CRUZ-Landim (2009) verified the presence of lipids in the secretion. In A. mellifera, the differences in size between the glands of virgin and egg-laying queens are non-significant, indicating that the amount of secretion is the same in both life stages. In this species, the substance responsible for identifying the queen, the queen's substance, is produced in the mandibular gland. Nevertheless, the possibility of an additional recognition function cannot be overlooked. If the mandibular gland is removed, the queen is still able to attract workers for normal courtship (Velthuis \& Van-Es 1964). This ability has been attributed to the possible presence of additional sources of queen pheromone. Poiani \& Cruz-Landim (2009) found lipids in the CSG secretion and suggested these glands as possible sources of additional pheromones. The CSG secretion is delivered to the tongue and may be spread over the body, from where the workers would collect it and distribute it through the colony by trophalaxis.

In conclusion, it is reasonable to propose that the CSG probably play different roles in workers and queens in the two species in this study. However, the chemical nature of the secretion and the developmental behavior of the glands suggest that this secretion plays a pheromonal role in every case.

\section{ACKNOWLEDGEMENTS}

The authors gratefully acknowledge the financial support of CAPES (Coordenação de Aperfeiçoamento de Pessoal de Nível Superior).

\section{LITERATURE CITED}

Bertsch, A.; H. Schweer; A. Titze \& H. TanaKa. 2005. Male labial gland secretions and mitochondrial DNA markers support species status of Bombus cryptarum and Bombus magnus (Hymenoptera, Apidae). Insectes Sociaux 52 (1): 45-54. doi: 10.1007/s00040-004-0761-1.

Submitted: 23.VII.2009; Accepted: 19.IX.2010. Editorial responsibility: Gabriel L.F. Mejdalani
Cruz-Landim, C. 1967. Estudo Comparativo de Algumas Glândulas das Abelhas (Hymenoptera, Apoidea) e Respectivas Implicações Evolutivas. Arquivos de Zoologia 15 (3): 177290.

Delage-Darchen, B.; S. Tabec \& R. Darchen. 1979. Secretion Enzymatique des Glandes Salivaires et de L'Intestin Moyen d'une Abeille Sans Dard, Apotrigona nebulata (Sur.) (Hyménoptères, Apidés). Annales des Sciences Naturelles Zoologie et Biologie Animale 13: 261-267.

Heselhaus, F. 1922. Die Hautchüsen der Apiden und Verwandten Formen. Zoologische Jahrbuecher Abteilung fuer Anatomie und Ontogenie der Tiere 43: 363-464.

Inglesent, H. 1940. Zymotic function of the pharingeal and thoracic and post-cerebral glands of Apis mellifera. Journal of Biochemistry 34: 1415-1418.

Jarau, S.; M. Hancir; R. Zucchi \& F.G. Barth. 2004. A Stingless Bee Uses Labial Gland Secretions for Scent Trail Communication (Trigona recursa Smith, 1863). Journal of Comparative Physiology A: Neuroethology, Sensory, Neural and Behavioral Physiology 190 (3): 233-239. doi: 10.1007/ s00359-003-0489-9.

Katzav-Gozansky, T.; V. Soroker; A. Ionescu; G.E. Robinson \& A. HefeTz. 2001. Task-related chemical analysis of labial gland volatile secretion in worker honeybees (Apis mellifera ligustica). Journal of Chemical Ecology 27 (5): 919-926. doi: 10.1023/A:1010330902388.

Poiani, S.B. \& C. Cruz-Landim. 2009. Cephalic salivary gland ultrastructure of worker and queen eusocial bees (Hymenoptera, Apidae). Animal Biology 59: 299-311. doi: 10.1163/ 157075609 X454935.

Schorcopf, D.L.P.; S. Jarau; W. Francke; R. Twele; R. Zucchi; M. Hancir; V.M. Schmidt; M. Ayasse \& F.G. Barth. 2007. Spitting out information: Trigona bees deposit saliva to signal resource locations. Proceedings of the Royal Society, B-Biological Sciences 274: 895-898. doi: 10.1098/rspb.2006.3766.

Simpson, J. 1960. The Functions of the Salivary Glands of Apis mellifera. Journal of Insect Physiology 4 (2): 107-121.

Simpson, J. 1961. The salivary glands of Apis mellifera and their significance in caste determination. Symposia Genetica et Biologica Italica 10: 173-188.

Simpson, J. 1963. The source of the saliva honeybees use to moisten materials they chew with their mandibles. Journal of Apicultural Research 2 (2): 115-116.

Simpson, J.; I.B.M. Riedel \& N. Wilding. 1968. Invertase in the hypopharyngeal gland of the honeybee. Journal of Apicultural Research 7 (1): 29-36.

Velthuis, H.H.W. \& J. Van-Es. 1964. Some functional aspects of the mandibular glands of the queen honeybee. Journal of Apicultural Research 3: 11-16. 